\section{How to diagnose axial spondyloarthropathy early}

\section{N Barkham, H Marzo-Ortega, D McGonagle, P Emery}

\section{A proposed algorithmic approach may be useful in the early detection of AS}

$\mathrm{P}$ hysicians' perceptions of the spondyloarthropathies are changing. Ankylosing spondylitis (AS), the prototype of this group, has traditionally been considered a rare disease with few therapeutic options. In addition, diagnosis is difficult, sometimes delayed for decades, mainly owing to the lack of sensitivity of the traditional imaging method, radiography, to detect the hallmark of AS, sacroiliitis. Also, the widespread perception of these diseases as "innocuous" or having a good outcome has hampered the development of protocols for defining early disease and identifying those patients who would benefit from early treatment.

\section{PROBLEMS OF AS}

It is now clear that these assumptions are incorrect. Ankylosing spondylitis is more common than previously estimated, with some studies suggesting a prevalence as high as $1 \% .{ }^{1}$ Importantly it affects people at a time when they are economically active (most commonly in the third decade), and the disease has a major impact on a person's ability to work. Recent evidence from a survey from our group shows that a high proportion of patients with AS still in work have major problems suggesting imminent job loss. ${ }^{2}$ In addition, the assumption of a good clinical outcome has recently been challenged, with 70\% of patients progressing to fusion of the spine by $10-15$ years. ${ }^{34}$ Mortality is also increased by 1.5-4 times that of the general population, ${ }^{5}$ and a $12 \%$ decrease in survival over 40 years has been noted. ${ }^{6}$

\section{EARLY AS}

Perhaps the main hurdle faced by the clinician has been the inability to establish a diagnosis early enough to allow treatment to be started. One of the difficulties is the non-specific nature of its symptomatology. In the case of rheumatoid arthritis (RA) the development of pain and swelling in "functional" joint groups such as the hands will make the patient seek medical advice soon, whereas this is not the case in AS. "Early" AS may present with peripheral enthesopathy or most commonly with inflammatory back pain, both symptoms that may be underrated by patients as they attempt to adjust to living with them. Our working definition of inflammatory back pain, defined almost three decades $\mathrm{ago}^{7}$ (table 1 ), is still not sufficiently robust to guide therapeutic interventions, as patients with mechanical back pain or degenerative arthritis of the spine will also complain of early morning stiffness. In addition, other markers of disease activity, such as the presence of raised inflammatory markers in serum, are not consistently found in these patients and are known to be unreliable markers for active inflammation, which will not aid the diagnosis. ${ }^{8}$

\section{NEW IMAGING METHODS}

The limitations of conventional radiography have already been mentioned but the advent of new imaging methods, especially magnetic resonance imaging (MRI), has facilitated the possibility of early diagnosis of AS. One study showed that MRI defined bone oedema representing sacroiliac joint osteitis, and predicted the development of radiographic sacroiliitis with a sensitivity of $85 \%$ and a specificity of $47 \%$. $^{9}$ However, evidence that these abnormalities predict the future ossification and fusion of

\section{"MRI has increased the possibility of early diagnosis of $\mathrm{AS}$, and TNFa blocking drugs have greatly im- proved its management ${ }^{\prime \prime}$}

So far, two groups have developed MRI scoring systems for sacroiliac and spinal pathology sensitive to change, ${ }^{10}{ }^{11}$ and initiatives are continuing to standardise the use of MRI as an outcome measure ${ }^{12}$ More research is needed in this area to better define the role of MRI.

\section{DRUG TREATMENT}

However, the biggest advance occurred with evidence of the efficacy of tumour the spine is still not available. necrosis factor $\alpha$ (TNF $\alpha$ ) blocking drugs, which have revolutionised the approach to the management of the spondyloarthropathies. Traditionally, treatments such as non-steroidal anti-inflammatory drugs (NSAIDs) and physiotherapy, although useful in a number of patients, in others fail to demonstrate a clear level of efficacy. Also, studies of conventional disease modifying antirheumatic drugs such as sulfasalazine, although successful in the treatment of inflammatory bowel disease, which is a common subclinical feature of AS, are only moderately efficacious for peripheral arthritis in patients with AS and not at all for axial disease. Likewise, the small number of studies carried out with methotrexate in chronic AS have not shown great efficacy, and this drug is not widely used. Recently, a bisphosphonate-namely, pamidronate, has been used, with one randomised controlled trial showing efficacy, ${ }^{13}$ but the acute phase response remained unchanged; further studies in this area are needed. The demonstration of the efficacy of anti-TNF agents in AS is the first significant therapeutic advance since the introduction of NSAIDs. Remarkable effects on the symptomatology have been shown in recent studies. $^{14}$ On MRI the inflammatory changes in the sacroiliac joint and spine often regress or improve, but it is yet to be shown whether this will represent a true modifying effect and will prevent joint fusion. ${ }^{15}$

\section{EARLY INTERVENTION}

With new diagnostic techniques and potentially major disease modifying treatments, the question of whether the severity of the disease is secondary to delay in treatment becomes relevant. There are few data relating to the prognosis in early disease after anti$\mathrm{TNF} \alpha$ treatment, although individual cases suggest that those treated early before radiographic changes have the best outcome. ${ }^{10}$ Certainly, the analogy with RA would suggest that these drugs are most effective when used early. ${ }^{16}$ Thus the possibility arises that early intervention in appropriate patients with targeted treatment could lead to major improvements in outcome. This pressure for early diagnosis has been translated into the first attempts to accurately define the early phase of disease. In this journal Rudwaleit et al analyse the criteria for diagnosing inflammatory back disease early. ${ }^{17}$ They examined the diagnosis in a variety of different situations and looked at the relative likelihood of correct diagnosis. In the process they provide much useful information for those involved in the management of inflammatory back 


\begin{tabular}{|lll|}
\hline Table 1 & Working definition of inflammatory & back pain \\
\hline Question & Response & Points \\
\hline Age at onset of back discomfort & $\geqslant 40$ & 0 \\
& $<40$ & 1 \\
Onset & Insidious & 1 \\
& Not insidious & 0 \\
Persistence of back discomfort (months) & $<3$ & 0 \\
Associated with morning stiffness & $\geqslant 3$ & 1 \\
Response to exercise & No & 0 \\
& Yes & 1 \\
& Improves & 1 \\
Score $=$ sum of findings present. & No improvement & 0 \\
Interpretation: minimum score $=0$; maximum score $=5$. A score $\geqslant 4$ indicates that inflammatory back \\
pain is present.
\end{tabular}

disease. Particularly useful is the algorithm aimed at general practitioners or non-specialists, with the simple message that inflammatory back pain by history and HLA-B27 indicates the necessity for an MRI scan for diagnosis. However, there is an intrinsic problem in this approach given that the "gold standard" for diagnosis that was used to derive the proposed algorithm was the development of radiographic changes. It is known that these occur only in established disease and therefore the validity of this approach could be questioned when transferred to the stage before $x$ ray change has taken place. Nevertheless, the authors had to start somewhere and they have done an excellent job with the tools available to them. This algorithmic approach now needs to be evaluated prospectively with MRI outcomes in the early inflammatory back pain clinic. If validated, it could be applied to identify patients eligible for treatment with biological agents. The health economics justify such an intervention because successful treatment would allow a significant number of employed subjects to remain at work during their most productive years.

Ann Rheum Dis 2004;63:471-472.

doi: 10.1136/ard.2003.014589

\section{Authors' affiliations}

N Barkham, H Marzo-Ortega, D McGonagle, P Emery, Academic Unit of Musculoskeletal

Disease, University of Leeds, UK

Correspondence to: Professor P Emery, Academic Unit of Musculoskeletal Disease, 1st Floor, Leeds General Infirmary, Great George Street, Leeds LSI 3EX, UK;

p.emery@leeds.ac.uk

\section{REFERENCES}

1 Braun J, Bollow M, Remlinger G, Eggens U, Rudwaleit $M$, Distler $A$, et al. The prevalence of spondyloarthropathy in HLA-B27 positive and negative blood donors. Arthritis Rheum 1998;41:58-67

2 Barkham N, Kong K, Fraser A, Tennant A Emery $P$. The unmet need for biologic therapy in ankylosing spondylitis [abstract]. ACR abstracts, 2003.

3 Gran JT, Skomsvoll JF. The outcome of ankylosing spondylitis: a study of 100 patients. Br J Rheumato 1997;36:766-71.

4 Carette S, Graham D, Little H, Rubenstein J, Rosen P. The natural disease course of ankylosing spondylitis. Arthritis Rheum 1983;26:186-90.

5 Lehtinen K. Mortality and causes of death in 398 patients admitted to hospital with ankylosing spondylitis. Ann Rheum Dis 1993;52:174-6.

6 Khan MA, Khan MK, Kushner I. Survival amongst patients with AS: a life-table analysis. J Rheumatol 1981;8:86-90.

7 Calin A Porta J, Fries JF, Schurman DJ. Clinical history as a screening test for ankylosing spondylitis. JAMA 1977;237:2613-14.

8 Spoorenberg $A$, van der Heijde D, de Klerk E, Dougados $M$. Relative value of ESR and CRP in assesment of disease activity in ankylosing spondylitis. J Rheumatol 1999;26:980-4.

9 Oostveen J, Prevo R, den Boer J, van de Laar M. Early detection of sacroilitis on magnetic resonance imaging and subsequent development of sacroilitis on plain radiography. prospective, longitudinal study. J Rheumatol 1999;26:1953-8.

10 Marzo-Ortega H, McGonagle D, O'Connor P, Emery P. Efficacy of etanercept in the treatment of entheseal pathology in resistant spondyloarthropathy. Arthritis Rheum 2001;44:2112-17.

11 Braun J, Baraliakos X, Golder W, Brandt J, Rudwaleit $M$, Listing J, et al. Magnetic resonance imaging examinations of the spine in patients with ankylosing spondylitis, before and after successful therapy with infliximab. Arthritis Rheum 2003:48: 1126-36.

12 Marzo-Ortega $\mathbf{H}$. Interreader agreement in the assessment of magnetic resonance imaging of the sacroiliac joints in spondyloarthropathy-the $1^{\text {st }}$ MISS study [abstract]. Arthritis Rheum 2002;46(suppl):S428.

13 Maksymowych WP, Jhangri GS, Fitzgerald AA, LeClercq S, Chiu P, Yan A, et al. A 6 month randomised, controlled, double-blind, dose response comparison of intravenous pamidronate $(60 \mathrm{mg}$ versus $10 \mathrm{mg})$ in the treatment of NSAID refractory AS. Arthritis Rheum 2002;46:766-73.

14 Sieper J, Braun J. New treatment strategies in ankylosing spondylitis: Proceedings of the Ankylosing Spondylitis workshop, Berlin Germany, 18-19 January 2002. Ann Rheum Dis 2002;61(suppl III):iiil-2.

15 Marzo-Ortega H, Emery P, McGonagle D. The concept of disease modification in spondyloarthropathy. J Rheumatol 2002;29:1583-5.

16 Quinn M, Conaghan P, Greenstein A, O'Connor P, Karim Z, Fraser A, et al. Sustained response in early poor prognosis RA after withdrawal of infliximab therapy [abstract]. Arthritis Rheum 2002;(suppl) abstr 6:3416.

17 Rudwaleit M, van der Heijde D, Khan MA, Braun J, Sieper J. How to diagnose axial spondyloarthritis early? Ann Rheum Dis 2004;63:535-43. 